\title{
O ACONTECIMENTO TEATRAL COMO PROPOSTA POLÍTICA, PARALELOS ENTRE O TEATRO do OPRIMIdo E O TEATRO Pós- DRAMÁTICO ${ }^{1}$
}

Heloisa Marina da Silva

Stephan Baumgartel

\section{RESUMO}

O teatro pós-dramático, corrente estética estudada principalmente pelo teórico alemão Hans Thies-Lehmann, tem como uma de suas características a exploração do teatro como acontecimento, da particularidade de ser uma tipo de arte que acontece na presença mutua entre aqueles que a executam e seus respectivos espectadores. Assim também ocorre na proposta de Augusto Boal: o teatro do oprimido. Entretanto cada estética apresenta propostas políticas particulares, apresentando pontos de convergencia e divergia, melhores explorados no decorrer desse trabalho.

PALAVRAS-CHAVES: Teatro pós-dramático, teatro do oprimido, estética teatral.

Esse trabalho se propõe a fazer um breve paralelo entre as experiências que a estética do teatro pós-dramático e do teatro do oprimido propõe no que diz respeito ao momento de encontro entre público e àqueles que realizam a encenação teatral. A idéia é a de discutir quais são os pontos de convergência e divergência dentro dessas estéticas, sendo que o foco está nas ressonâncias que tais estéticas se propõe a atingir no seio da sociedade contemporânea.

Uma característica importante do teatro pós-dramático é a consciência do fato de que o ato teatral se configura enquanto acontecimento, ou seja, a estética pós-dramática se apropria da situação teatral. A situação teatral, o fato do momento artístico se constituir durante a imediata presença entre artistas e seu respectivo público, é dessa forma explorado de modo consciente pelos artistas contemporâneos. Já não se busca mais, como era o caso do drama burguês, criar uma atmosfera de ilusão, onde o palco pretende ser o mundo e a encenação um recorte da vida real que se encontra além das

${ }^{1} \mathrm{O}$ teatro pós-dramático na Alemanha: contextos estéticos e culturais. CEART-UDESC. Coordenado pelo professor Stephan Baumgartel - DAC. Bolsista de iniciacao científica: Heloisa Marina da Silva. PROBIC. 
paredes do edifício teatral. Para Hans Thies-Lehmann "teatro significa tempo de vida em comum que atores e espectadores passam juntos no ar que respiram juntos daquele espaço em que a peça teatral e os espectadores se encontram frente a frente". (LEHMANN, 2007, p. 18).

Através e por causa dessa consciência que o teatro adquire da situação teatral as fronteiras entre arte e vida começam a ser borradas; é necessário todavia destacar que o foco principal não se encontra, como ocorreu com as performances dos anos 60 , em criar uma arte que se configura como a própria vida real. A indagação feita entre os limites entre arte e vida visa detectar as lacunas, contradições e rachaduras dentro do sistema artístico e social. O teatro pós-dramático indaga portanto o alcance do impacto da arte na vida, bem como o da vida na arte. O teatro de agora, consciente de sua própria característica ficcional, começa a jogar com elementos hiper-realistas que visam confundir o espectador e por vezes os próprios artistas: até que ponto determinado acontecimento fez parte do espetáculo ensaiado e até que ponto ele se deu de modo espontâneo e com um grau de realidade pragmática mais alto? Isso ocorre, entre outros motivos, em função do fato de que agora o espectador passa a ser co-autor da cena, do conjunto dramático, um participante que entretanto não interpreta, não faz de conta, apenas age, como ele mesmo agiria no seu dia-a-dia. Através de tais circunstancias a delimitação precisa entre o que é teatro (momento ensaiado que faz parte de uma ficção) e o que constitui o presente pragmático parece não ser mais tão facilmente detectável. Tal esfumaçamento entre arte e vida é também fruto de um teatro que tem rompido com as paredes do edifício teatral, fazendo espetáculos em lugares múltiplos e principalmente propondo pontos de vistas diversos aos seus espectadores.

Creio ser interessante destacar dentro de qual contexto social esse teatro parece ter emergido, e como então sua nova forma pretende dialogar com esse contexto. Para Guy Debord é possível identificar a sociedade contemporânea enquanto 'sociedade de espetáculo', pois segundo Debord (1997, p. 13-14):

Toda a vida das sociedades nas quais reinam as modernas conduções de produção se apresenta como uma imensa acumulação de espetáculos. Tudo que era vivido diretamente tornou-se uma representação. (...) O espetáculo apresenta-se ao mesmo tempo como a própria sociedade, como uma parte da sociedade e como instrumento de unificação. Como parte da sociedade, ele é expressamente o setor que concentra todo o olhar e toda a consciência. Pelo fato de esse setor estar separado, ele é o lugar do olhar iludido e da falsa consciência; a unificação que realiza é tão-somente a linguagem oficial da separação generalizada. 
O que Debord propõe é que a sociedade atual vive num mundo onde as fronteiras entre real e espetacular, entre fato e ficção, não são mais passíveis de serem delimitadas, “(...) a realidade vivida é materialmente invadida pela contemplação do espetáculo e retoma em si a ordem espetacular à qual adere de forma positiva. (...) a realidade surge no espetáculo, e o espetáculo é real". (Ibidem, p. 15). Para Debord essa relação espetacular que a vida cotidiana adquire é problemática uma vez que a contemplação leva ao entorpecimento, a uma falsa ilusão de se estar vivendo o que na verdade apenas se contempla; o homem, ao se identificar com imagens dominantes, deixa de perceber sua existência e seus desejos pessoais. (Ibidem, p. 15).

O teatro encontra então o desafio de estabelecer uma tensão produtiva entre a encenação enquanto encontro social e apresentação espetacular pois o fenômeno teatral almeja distinguir-se do que Debord chamou de espetáculo. A diferença consiste no fato de que o intuito dos teatros criados dentro da lógica representacional pós-dramática é justamente fazer do público um público consciente das lógicas espetaculares existentes no teatro e na vida, e neste sentido, co-responsável pela apresentação do espetáculo, através do conflito proposto no aqui e agora do encontro teatral (não entre personagens mas entre as pessoas que participam desse encontro).

Também Augusto Boal já na década de 60 parece ter baseado seus estudos e suas buscas artísticas a partir da idéia de que o teatro se constitui enquanto acontecimento. Um dos episódios que o impulsionou a criar uma proposta poética própria, a qual ele chamou de Teatro do Oprimido, ocorreu quando o grupo Teatro de Arena, do qual ele fazia parte, havia feito uma apresentação em uma Liga Camponesa no Nordeste. Ao final de representação, que falava de luta e derramamento de sangue em defesa da terra, um dos camponeses se levantou com armas (reais e não cenográficas) convidando os atores a lutar, verdadeiramente, por seus ideais. Muito sem jeito os atores se recusaram a derramar seu sangue em nome da terra, muito embora pregassem isso através de seus discursos teatrais ${ }^{2}$. A partir de então parece ter ficado claro a Boal que o teatro acontece no momento presente, de forma que qualquer espectador pode intervir, manifestar-se, e até mesmo questionar o que vê, como de fato ocorreu nesse episódio relatado. Por causa o tipo de teatro que ele vinha realizando, que de certo forma se proponha a pregar uma moral, ou um ideal, já não lhe parecia mais viável, pelo menos não da maneira como até então o tinha feito.

BOAL, Augusto. O arco-íris do desejo. Civilização Brasileira. Rio de Janeiro. 1996. p. 17-19. 
Boal chega dessa forma à conclusão de que não há como demonstrar para seus espectadores o modo como eles devem agir, uma vez que ele mesmo não iria proceder de acordo com o que elucidava. Em função dessa experiência Augusto Boal começa a elaborar uma outra maneira de conceber o fazer teatral; suas pesquisas passam a buscar um modo através do qual o teatro possa estabelecer relações conscientes e concretas com seu público. Assim, de modo semelhante como certas vezes ocorre no teatro pósdramático, seu foco se desvia da qualidade estética e passa a estar mais centrado no processo. É preciso notar que, todavia, a importância que o Teatro do Oprimido dá ao processo vai além de como ocorre no teatro pós-dramático, uma vez que não raro a estética do Oprimido chega a dispensar inclusive a participação tanto de artistas profissionais quanto do momento espetacular, onde um trabalho previamente elaborado é apresentado; característica essa que não encontramos nas companhias teatrais que operam dentro da estética pós-dramática.

Ainda assim a proposta teatral mais elaborada que Boal criou, o Teatro-Fórum, se constitui de fato enquanto espetáculo, previamente ensaiado (seja ele feito por profissionais ou amadores) e em seguida apresentado. Essencial à dramaturgia do oprimido é justamente a presença bipolar entre opressores e oprimidos, ou seja, uma situação de opressão que deverá ser levada à cena. Tal situação de opressão é colocada em cena sempre em função da necessidade/vontade exprimida pelos participantes dessa prática no decorrer das oficinas de teatro e ensaios. O Teatro-Fórum deverá acontecer em algum espaço público qualquer, não necessariamente um espaço planejado para o teatro, na presença de espectadores que não tenham participado do processo de construção do espetáculo. Os espectadores, que num primeiro momento assistem a tudo com uma certa passividade, não devem ser dar ao luxo de simplesmente contemplar a obra artística que vem sendo a eles apresentada, pois num segundo momento serão eles mesmos convidados a fazer parte concretamente do evento representacional.

\section{Espect-atores são o foco}

O foco da pesquisa de Boal, que o levou a criação do Teatro do Oprimido, esteve dessa forma sempre centrado no papel que deveria ser legado ao espectador no enquanto do acontecimento teatral. Para Boal era necessário uma revisão urgente do papel desse agente da situação teatral:

(...) O espectador, ser passivo, é menos que um homem e é necessário re-humanizá-lo, restituir-lhe sua capacidade de ação em toda sua plenitude. Ele dever ser também o sujeito, 
um ator, em igualdade de condições com os atores, que devem por sua vez ser também espectadores. Todas estas experiências de teatro popular perseguem o mesmo objetivo: a liberação do espectador, sobre quem o teatro se habituou a impor visões acabadas de mundo. E considerando que quem faz teatro, em geral, são as pessoas direta ou indiretamente ligadas às classes dominantes, é lógico que essas imagens acabadas sejam imagens da classe dominante. $\mathrm{O}$ espectador do teatro popular (o povo) não pode continuar sendo vítima passiva dessas imagens. (BOAL, 1991, p. 180).

Ou seja, seu principal objetivo é o de legar ao espectador não mais uma função passiva contemplativa durante o evento teatral, mas sim transformá-lo em sujeito ativo, atuante, co-autor. Essa é também uma das propostas do teatro pós-dramático. Porém ainda que o teatro pós-dramático negue as estruturas do drama burguês, que promove um teatro de modelo acabado, sua investida política parece ser muito mais sutil de como ocorre nas propostas elaboradas por Boal. Essa diferença pode ser observada no próprio papel que cada uma dessas propostas estéticas parece querer atribuir ao espectador. Está claro que ambas buscam tira-lo de uma posição cômoda e passiva, mas no teatro de Boal ocorre que

O espectador não delega poderes ao personagem para que ele atue nem para que pense em seu lugar: ao contrário, ele mesmo assume um papel protagônico., transforma a ação dramática inicialmente proposta, ensaia soluções possíveis, debate projetos modificadores: em resumo, o espectador ensaia, preparando-se para a ação real. (Ibidem, p. 138).

Já no teatro pós-dramático é comum que o espectador se depare com a falta de uma fabula tradicional (com começo, meio e fim), ele estará diante de uma obra que não raro se apresenta fragmentada, não está aberta apenas porque o final é incerto, mas todo seu enredo parece não seguir uma lógica linear, um continuo. A posição ativa que tais obras esperam do espectador é de que, ao se deparar com a obra, ele construa uma visão própria frente ao que lhe é apresentado, uma vez que não existe um todo concreto e por assim dizer acabado, as visões que surgiram em relação ao espetáculo serão múltiplas e particulares, mas não serão encenadas pelos espectadores, como acontece no teatro de Boal. "Ao exercer seu caráter e real de acontecimento em relação ao publico, o teatro descobre sua possibilidade de ser não apenas um acontecimento de exceção, mas uma situação provocadora para todos os envolvidos". (LEHMANN, 2007, p. 172). Com relação a não linearidade (a ausência de uma fábula) dentro da estética pós dramática, Lehmann diz que 
(...) Foi determinante para a estética teatral o deslocamento da obra para o acontecimento. É certo que o ato da observação, as reações e as "repostas" latentes, ou mais incisivas dos espectadores desde sempre haviam constituído um fator essencial da realidade teatral, mas nesse momento se tornam um componente ativo do acontecimento, de modo que a idéia de uma construção coerente de uma obra teatral acaba por se tornar obsoleta: um teatro que inclui as ações e expressões dos espectadores como um elemento de sua própria constituição não pode se fechar em um todo nem do ponto de vista prático nem teórico. Assim, o acontecimento teatral torna explícitas tanto a processualidade que lhe é própria quanto a imprevisibilidade nela implícita. (Ibidem, p. 100)

Já no Teatro-Fórum a participação ativa do espectador não se limita a pequenos momentos que ele eventualmente possa fazer parte da cena, nem tão pouco se contenta em fazê-lo apenas refletir, essencial à proposta desse teatro é justamente a transformação do espectador em protagonistas. Em especial a opressão representada deve ser observada pelo público que, num segundo momento da representação, deverá gritar a palavra pára, e então subir até o palco e demonstrar o que ele mesmo faria, caso se encontrasse na situação demonstrada pelos artistas, é nesse momento que o espectador passa a fazer parte da obra e é justamente quando passamos a nos perguntar se o evento que então se realiza se constitui de fato enquanto ato teatral. O espectador que agora assume a cena representa, age, é um personagem ou apenas demonstra o que ele mesmo faria? Para Boal essa participação do espectador dentro do acontecimento teatral era tão fundamental que ele passou a chamar os espectadores de espect-atores.

\section{O Coringa}

Para garantir essa participação ativa dos espectadores o Teatro-Fórum conta com o personagem Coringa, uma espécie de mestre de cerimônias, que tem a função de manter o público sempre a par e consciente do que se passa, bem com estimular a participação destes dentro do acontecimento teatral. Ele deve também sempre tomar posição quando há desvios dentro da proposta do Fórum. Por exemplo, tendo em vista que o que Boal propõe é que o teatro sirva como ensaio das ações que deverão ser praticadas futuramente, as propostas apresentadas pelos espect-atores devem ser plausíveis, nunca propostas mágicas ou demasiadamente difíceis de serem concretizadas na vida real. É também função do coringa assegurar-se de que a platéia assiste a tudo com total entendimento do que se passa. Ele não deve ser nunca impositivo, mas precisa 
ser ativo, se fazer presente, deve ser estimulador, de modo a encorajar a participação dos espect-atores dentro da cena apresentada. (BOAL, 2000, p.330).

\section{Confluência e divergências e a posição política de ambas a estáticas}

Ainda que para Boal o fundamental no decorrer de uma seção de Teatro Fórum não era chegar a uma conclusão cabal, generalizada, acreditando que provocar um bom debate seria suficiente, sendo que a conclusão final, bem como a pratica concreta que se pretende que acontece após tais seções teatrais, concerne a consciência individual de cada qual, sua propostas sempre se centrou no intuito de que o teatro pudesse apresentar-se enquanto ensaio de ações que deveriam ser praticadas na vida concreta daqueles que participavam do acontecimento cênico. Alguns dos princípios da estética do Oprimido apontados por Boal são: “(...) transformação do espectador em protagonista; a tentativa de, através dessa transformação, modificar a sociedade, e não apenas interpreta-la". (Ibidem, p. 319).

É justamente nesse ponto que Teatro do Oprimido e Teatro pós-dramático divergem. O teatro pós-dramático não busca de modo algum mudar a realidade de modo concreto. Sua intenção é causar no espectador um assombro, perante a realidade concreta, que ele se sinta incomodado e que esse incomodo o faça refletir, o tornado-o talvez, consciente da espetacularização presente na vida cotidiana. O teatro pósdramático se pretende político não por estar em consonância a uma ideal político específico ou a uma corrente política de nível mais ou menos partidário, mas sim por propor um caráter perturbador em seu modo de constituir-se. Lehmann afirma que o teatro “(...) Para ser político deve conter o fator de transgressão, um teatro político feito para um grupo que irá reafirmar suas convicções, não apresenta o fator de transgressão e, portanto não é político”. (LEHMANN, 2007, p. 414). Ou seja, para ele “(...) Na maior parte das vezes, o teatro político não passava de um ritual de confirmação para aqueles que já estavam convencidos". (Ibidem, p. 409).

Essa afirmação de Lehmann talvez venha de encontro com as práticas propostas por Boal, mas essa afirmação pode também ser questionada uma vez que ele deixava a cargo dos fazedores de teatro (atores ou amadores) a escolha dos temas, bem com as propostas para soluções de conflito. Entretanto não se pode negar que a base do Teatro do Oprimido (a sempre representação de uma situação onde se opõe opressores e oprimidos) nasce de uma corrente política explicita (o marxismo) e desse modo não podemos deixar de considerar, e acredito que nem Boal o deixaria, que seu teatro também se presta a perpetuação/afirmação dessa corrente político-filosófica. 
Ainda assim é louvável que o teatro do Oprimido tenha apresentada uma maneira concreta de incluir o público (principalmente aquele não acostumado com o teatro) à situação teatral. Podemos dizer que é essa também a tendência do teatro pósdramático, uma busca sim, mas que não raro se frustra. Esse fato que pode ser exemplificado através da seguinte afirmação de Lehmann:

\footnotetext{
A experiência do real e a falta de ilusões fictícias com freqüência suscitam uma decepção quanto à redução, à manifesta "pobreza". As objeções a esse teatro se referem, por um lado, ao tédio de uma percepção puramente estrutural. Essas reclamações são tão velhas quanto a própria modernidade, e seu motivo é sobre tudo a má-vontade em admitir novos modelos de percepção. (Ibidem p. 164).
}

Talvez poderíamos aceitar que sua queixa encontrasse ressonâncias na Europa, onde ainda hoje o estado do bem estar social tem conseguido assegurar uma população bem alimentada e minimamente informada. No Brasil, onde ainda grande parte da população ainda é analfabetos funcionais, talvez possa parecer hipócrita querer apresentar um teatro de leitura difícil, e muitas vezes até ininteligível ao seu público. Por outro lado assumir tal ponto de vista pode trazer a tona uma conotação de que o povo brasileiro seria intelectuamente inferior ao europeo e por isso a leitura de um teatro que apresenta propostas contemporâneas não seria possível de ser feita. Fato esse que, todos sabemos bem, não é verdadeiro, uma fez que uma serie de grupos teatrais brasileiros tem atigindo profundo êxito ao realizarem montagens perfeitamente indendificavéis dentro da estética pós-dramática.

O Teatro pós-dramático por tanto não se desvincula do conceito político, apenas o considera a partir de outra perspectiva, o novo teatro portanto formula um novo saber cultural que atualmente não se encontra disponível em forma discursiva. É um saber performativo que não pode ser transmitido discursivamente através da língua, mas apenas experimentado no próprio corpo.

Ou seja, a experimentação, a indagação e concepção de sua prática, é não mais uma posição política partidária, fazem do teatro pós-dramático um teatro político. Em outras palavras o teatro pós-dramático se pretende político por causa da forma como se apresenta e não por causa de seu conteúdo.

No caso de Boal as duas coisas estão presentes: a forma aberta, que pergunta a seu público e o tira de uma situação contemplativa (aquela mesma criticada por Debord), mas também seu conteúdo é de caráter explicitamente político, se por lado ele 
dá abertura suficiente para que seu público se coloque, escolha de quais angustias ele irá falar ele não dá tamanha abertura de modo que seu modelo opressor/oprimido possa ser transgredido, seu público fica circunscrito dentro de uma visão política clara, e ele mesmo talvez não possa se dar conta disso.

Bibliografia

BOAL, Augusto. Jogos para atores e não atores. Civilização Brasileira. $3^{a}$ ed. Rio de Janeiro. 2000.

BOAL, Augusto. $\mathrm{O}$ teatro do oprimido e outras poéticas políticas. Civilização Brasileira. 6a ed. Rio de Janeiro. 1991.

BOAL, Augusto. O arco-íris do desejo. Civilização Brasileira. Rio de Janeiro. 1996.

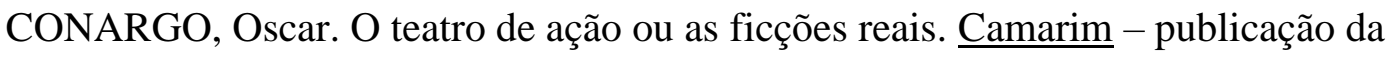
cooperativa paulista de teatro, São Paulo, n 39, ano 10, semestre 2007. p. 26-33

DEBORD, Guy. A sociedade do espetáculo. Rio de Janeiro: Contraponto, 1997.

FINTER, Helga. A teatralidade e o teatro. Camarim - publicação da cooperativa paulista de teatro, São Paulo, n 39, ano 10, semestre 2007. p. 8-19

LEHMANN, Hans-Thies. Teatro pós-dramático. Trad. Pedro Süssekind. São Paulo: Cosac \& Naify, 2007.

PRIMAVESI, Patrick. "Orte und Strategien postdramatischer Theaterformen." In: ARNOLD, Heinz Ludwig (org.) Theater fürs 21. Jahrhundert. München: Edition Text + Kritik, 2004, p. 8 - 25.

SZONDI, Peter. Teoria do drama moderno [1880 - 1950]. Trad. Luiz Sérgio Repa. São

Paulo: Cosac \& Naify, 2001. 